\title{
Seizures Associated with Spontaneous Subarachnoid Hemorrhage
}

\author{
M.B.M. Sundaram and F. Chow
}

\begin{abstract}
We analysed the charts of 131 consecutive cases of spontaneous subarachnoid hemorrhage - without arteriovenous malformations - for seizures. Convulsions occurred in 31 patients $(24 \%)$ and most often within 24 hours of bleeding. Motor manifestations of partial seizures were of no lateralizing value to aneurysm site. Early mortality, rebleeding and int racerebral hematoma were similar in both seizure and non-seizure groups. Late seizures were infrequent in survivors who had suffered seizures in the acute stage - thus questioning the necessity for routine, long term prophylactic anticonvulsants in these patients.
\end{abstract}

\begin{abstract}
RÉSUMÉ: Convulsions associées à une hémorragie sous-arachnoïdienne. Nous avons analysé les dossiers de 131 cas consécutifs d'hémorragie sous-arachnoïdienne spontanée - sans malformation artério-veineuse - pour déterminer la présence ou l'absence de convulsions. Trente-et-un patients ont présenté des convulsions, le plus souvent en dedans de 24 heures de l'hémorragie. Les manifestations motrices des crises partielles n'avaient pas de valeur quant à la latéralisation du site de l'anévrisme. La mortalité précoce, l'hémorragie subséquente et l'hématome intracérébral étaient aussi fréquents dans les deux groupes, soit avec convulsions et sans convulsion. Les convulsions d'apparition tardive étaient rares chez les survivants qui avaient souffert de convulsions à la phase aiguë — remettant ainsi en question la nécessité de prescrire de routine des anticonvulsivants à long terme chez ces patients.
\end{abstract}

Can. J. Neurol. Sci. 1986:13:229-231

Spontaneous subarachnoid hemorrhage (SSH) is a common neurological disorder and accounts for approximately $10 \%$ of all strokes. ${ }^{1.2}$ Complications such as rebleeding, vasospasm and hydrocephalus are well recognized and there is extensive literature on these topics. However, the subject of seizures in $\mathrm{SSH}$ has not attracted as much attention. Pioneer monographs ${ }^{3-11}$ and more recent large studies ${ }^{12-15}$ on SSH fail to discuss seizures in detail or make only brief comments on this complication. This is particularly evident for SSH not associated with arteriovenous malformations (AVM). We are aware of only 6 reviews ${ }^{16-21}$ in world literature (4 English, I Serbo-Croatian and I Chinese), about seizures in SSH of non-AVM etiology. In this paper, we analyse the following aspects: i) incidence, type and time of convulsions, ii) seizure laterlizing value for aneurysm site, iii) could intracerebral hematoma cause seizures, iv) do seizures affect early rebleeding and mortality and $v$ ) the need for longterm prophylactic anticonvulsants for patients who have suffered seizures in the acute stage.

\section{METHODS}

Spontaneous subarachnoid hemorrhage was defined as an acute neurological event leading to the presence of blood in subarachnoid space, confirmed by CT scan or/and cerebrospi- nal fluid examination in the absence of trauma. Cases associated with neonatal hypoxic encephalopathy, primary hypertensive intracerebral hematoma, cerebral and spinal vascular malformations, and those with chronic idiopathic epilepsy prior to hemorrhage were excluded; the remaining consecutive intracranial SSH cases, seen between December 1978 and June 1984, in our hospital were further analysed for seizures.

Seizure occurrence was inferred from i) sufficient witnessed description by the physician or nursing staff or ii) convincing description by relatives or ambulance personnel when seizures occurred outside the hospital and documentation by the admitting physician that they were seizures. Care was taken not to include events like decerebrate posturing and vague "blackouts". Only events that were independently agreed by both authors to be seizures were included.

Based on seizure onset in relation to bleeding, patients were separated into: i) Early seizure group, when seizures started within 2 weeks of hemorrhage and ii) Late seizure group, when onset was after 2 weeks. Number and type of seizures as well as details of anticonvulsant therapy were obtained.

Etiology of hemorrhage, rebleeding and mortality rates within 4 weeks of bleeding were determined for all cases from clinical, angiographic and autopsy data. Presence or absence of intra-

From the Department of Clinical Neurological Sciences. University Hospital, University of Saskatchewan

Received December 12, 1985. Accepted March 13, 1986

Reprint requests to: M. B.M. Sundaram, Department of Clinical Neurological Sciences, University of Saskatchewan Hospital. Saskatoon, Saskatchewan, Canada S7N 0X0 
cerebral hematoma was ascertained from CT and autopsy findings. Data from non-seizure group were used as "control" for comparison with seizure group.

\section{RESULTS}

131 consecutive patients seen during the 67 month study period were included in the study (55 males and 76 females; mean age 49 years, range 1 to 81 years). CT scan of the brain was available in 121 cases and CSF examination was performed in 37 (of these, 31 had CT examination as well). Cerebral angiograms were done in 104 patients. In 2 patients, the diagnoses were obtained exclusively from autopsy. Aneurysmal bleeding was the most common cause of SSH (Table 1). Patients surviving 4 weeks or more after hemorrhage were followed for a mean period of 23 months (range: 2 to 70 months).

\begin{tabular}{lccc}
\hline \multicolumn{4}{l}{ Table 1: Etiology of Subarachnoid Hemorrhage } \\
\hline $\begin{array}{c}\text { Non-seizure } \\
\text { Group }\end{array}$ & $\begin{array}{c}\text { Seizure } \\
\text { Group }\end{array}$ & Total \\
\hline Aneurysms & $\mathrm{N}$ & $\mathrm{N}$ & $\mathrm{N}$ \\
Unknown & 76 & 28 & 104 \\
Bleeding diatheses & $2 !$ & 2 & 23 \\
Hypertension & 2 & 1 & 3 \\
TOTAL & $\mathrm{I}$ & 0 & 1 \\
\hline
\end{tabular}

Seizures occurred in 31 ( 15 males, 16 females) of the 131 patients (24\%); they were partial with or without secondary generalization in 16 and apparently generalized from the onset in 15. Motor manifestations of partial seizures - eg. head turning, stiffening and clonic movements of limbs - did not always correlate with lateraliztion of aneurysm location. Eleven patients had a single isolated seizure and the remaining 20 each had 2 or more seizures.

Seizure onset was within 2 weeks of hemorrhage (early seizures) in 26 of 31 patients. In 19 of these, convulsions were noted within 24 hours of bleeding and in another two, between 24 and 48 hours (Table 2). Only 2 patients with early seizures continued to have attacks beyond 4 weeks.

\section{Table 2: Time of Seizures in Relation to Subarachnoid Hemorrhage}

i. Early Seizures (within the first 2 weeks) less than 24 hours of bleeding

24 to 48 hours

48 hours to 1 week

$-2$

1 to 2 weeks

$-3$

$-2$

ii. Delayed Seizures

(1st seizure more than 2 weeks after hemorrhage)

Of twenty-six patients with early seizures, 23 had convulsions in relation to the first bleed and 3 with rebleeding. Those who had convulsions with the first bleed did not have seizure recurrence with rebleeding.

Nine patients from the early seizure group of 26 died within 4 weeks of hemorrhage $(35 \%)$ - a mortality rate similar to that for non-seizure patients $(41 \%)$.

Delayed seizures (onset beyond 2 weeks) were noted in 5 cases. The total number of seizures per patient during follow-up ranged from 2 to 4 . There was no evidence of rebleeding at the time of seizures in any of these 5 patients.

The incidence of rebleeding and intracerebral hematoma within 4 weeks of hemorrhage did not differ between patients with and without seizures.

As will be seen from table 3 , infratentorial aneurysms were not associated with seizures; commonly occurring supratentorial aneurysms were represented in the seizure group without any particular site predilection.

Table 3: Locations of Aneurysms

\begin{tabular}{lccr}
\hline \hline & $\begin{array}{c}\text { Seizure Group } \\
\text { N }\end{array}$ & $\begin{array}{c}\text { Non-Seizure } \\
\text { Group } \\
\text { N }\end{array}$ & $\begin{array}{c}\text { Total } \\
\text { N }\end{array}$ \\
\hline Anterior communicating & 6 & 27 & 33 \\
Middle cerebral & 5 & 21 & 26 \\
Posterior communicating & 8 & 11 & 19 \\
Internal carotid & 4 & 8 & 12 \\
Anterior cerebral & 4 & 1 & 5 \\
Ophthalmic & 1 & 1 & 2 \\
Vertebrobasilar & 0 & 7 & 7 \\
Unknown & 2 & 21 & 23 \\
Others & 1 & 3 & 4 \\
\hline
\end{tabular}

Details of anticonvulsant therapy were available for 15 of the 17 survivors (beyond 1 month) in early seizure group; 8 were on prophylactic long-term anticonvulsants and one among them had single tonic-clonic seizure 8 months following bleeding; 7 were not given prophylactic long-term anticonvulsants and one of them had several partial motor seizures in a single day, 4 months after bleeding. None of the 5 cases from delayed seizure group was on prophylactic anticonvulsant at the time of first seizure.

Among the 59 survivors (beyond 1 month) of 100 non-seizure patients, 13 were placed on prophylactic anticonvulsants and the medications were continued for more than 3 months in only 5 patients (for 4 months in 1, for 5 months in 2 and for 8 months in 2).

\section{Discussion}

\section{Overall Seizure Incidence}

Previous studies on aneurysmal subarachnoid hemorrhage have quoted an incidence of seizures from $3 \%$ to $26 \%$. $^{4-6.8 .13-21}$ However, most of them included only early or late seizures and some were limited to those undergoing surgery. Hart et al ${ }^{18}-$ analysing both early and late seizures in an unselect non-AVM population - observed seizures in $26 \%$ a figure similar to ours and likely represents accurate overall seizure incidence.

\section{Early Seizures}

We have shown that seizures in SSH of non-AVM etiology occur most often within the first 24 hours of hemorrhage. In contrast, convulsions in bleeding AVM are more common prior to hemorrhage and occur in approximately 10 to $31 \%$ of cases. ${ }^{22-26}$ However, patients with AVM rarely have seizures at or closely after the hemorrhage - occurring in only 2 of 549 cases studied by Perret and Nishioka. ${ }^{25}$

Our findings also show that early seizures do not reliably predict long-term recurrence in survivors and such late convul- 
sions are infrequent when they do occur. This has important therapeutic implications (see below).

\section{Late Seizures}

Four percent incidence of new seizures in survivors beyond 1 month in our study and that by Hart et $\mathrm{al}^{18}$ is lower than the $10-11 \%$ found by other authors ${ }^{11.13 .16}$ — the difference may be explained by their longer follow-up. Rose and Harner, ${ }^{16}$ for example, observed that $10 \%$ incidence of late seizures noted from charts increased to $15 \%$ when survivors were brought back to a follow-up clinic.

Previous studies on late seizures do not specify the frequency of convulsions per patient. This appears to be low, totalling 2 to 4 attacks per patient with treatment during the mean 23 months follow-up in our patients.

\section{Pathogenesis of seizures}

This remains speculative and likely multifactorial. However, certain observations can be made from our study and review of previous literature. The high incidence of seizures within 24 hours of hemorrhage ( 19 of our 26 cases with early seizures) suggests that direct irritation of the cerebral cortex by blood could be one of the major factors responsible for early seizures. Vasospasm appears etiologically less important, as this complication occurs usually around 4 to 7 days after hemorrhage. That intracerebral hematoma occurred equally often among seizure and non-seizure patients, makes it an unlikely etiologic factor. Rose and Harner ${ }^{16}$ and Cabral et al ${ }^{17}$ observed that patients with middle cerebral artery aneurysms were more likely to suffer from seizures but we were unable to confirm this.

Late seizures are likely related to a number of factors including infarction ${ }^{16}$ and operative trauma. ${ }^{17}$ These and other factors like residual hemosiderin should be addressed further by controlled prospective clinical and autopsy studies.

\section{Long term anticonvulsants}

Seizures during follow-up are said to be "infrequent" and "easy to control". 13,16,7 Seizure recurrence following early seizures and number of convulsions in each patient, in our study, were low; when they did recur, there were equal numbers of cases from prophylactically treated and untreated groups ( 1 from each group). Although our numbers are small, these observations question the necessity for routine prophylactic long term anticonvulsants in patients with early seizures: we feel that such therapy could be initiated when seizures occur during follow-up and are recurrent.

\section{REFERENCES}

1. Uttley D. Subarachnoid hemorrhage. Br J Hosp Med 1978; 19: 138-154.

2. Heros RC, Zervas NT. Subarachnoid hemorrhage. Ann Rev Med 1983; 34: 367-75.

3. Fearnsides EG. Intracranial aneurysms. Brain 1916; 39: 224-296.
4. Magee CG. Spontaneous subarachnoid hemorrhage. The Lancet 1943; 245: 497-500.

5. Dandy WE. Intracranial arterial aneurysms. Comstock Publishing Co, lthaca. New York 1944. pp 13-14.

6. Hamby WB. Spontaneous subarachnoid hemorrhage of aneurysmal origin. JAMA 1948: 136: 522-528.

7. Hyland HH. Prognosis in spontaneous subarachnoid hemorrhage. Arch Neurol Psychiatr 1950; 63: 61-78.

8. Dekaban A. McEachern D. Subarachnoid hemorrhage, intracranial hemorrhage and intracranial aneurysms. Arch Neurol Psychiatr 1952; 60: 641-649.

9. Timberlake WH. Kubik CS. Follow-up report with clinical and anatomical notes on 280 patients with subarachnoid hemorrhage. Trans Am Neurol Assoc 1952: 77: 26-30.

10. McKissock W, Paine KWE, Walsh LS. An analysis of the results of treatment of ruptured intracranial aneurysms. J Neurosurg 1960; 17: 762-776.

11. Walton JN. Subarachnoid hemorrhage. E and S Livingstone Ltd. Edinburg and London 1956. p 59.

12. Locksley $\mathrm{HB}$. Report on the cooperative study of intracranial aneurysm and subarachnoid hemorrhage. Section V. Part I. Natural history of subarachnoid hemorrhage. intracranial aneurysms and arteriovenous malformations. J Neurosurg 1966; 25 : 219-239.

13. Storey PB. Psychiatric sequelae of subarachnoid hemorrhage. $\mathrm{Br}$ Med J 1967: iii: 261-266.

14. Winn HR, Richardson $A E$ et al. The long-term prognosis in untreated cerebral aneurysms: II. Late morbidity and mortality. Ann Neurol 1978; 4: 418-426.

15. Sundt TM, Kobayashi S et al. Results and complications of surgical management of 809 intracranial aneurysms in 722 cases. J Neurosurg 1982: 56: 753-765.

16. Rose CF, Sarner M. Epilepsy after ruptured intracranial aneurysm. Br Med J 1965: i: 18-21.

17. Cabral RJ, King TT, Scott DF. Epilepsy after two different neurosurgical approaches to the treatment of ruptured intracranial aneurysm. J Neurol Neurosurg Psychiatry 1976: 39: 1052-1056.

18. Hart RG, Byer JA et al. Occurrence and implications of seizures in subarachnoid hemorrhage due to ruptured intracranial aneurysms. Neurosurgery 1981; $8 ; 417-421$.

19. Witoonpanich R, Bunyaratavej S. Vejjajiva A. Epileptic seizures in intracranial aneurysm. J Med Assoc Thailand 1980; 63: 192-195.

20. Ristic J, Gospavic J, Krstic S. Epileptic manifestations in subarachnoid hemorrhage. Neuropsihijatrija 1971: 19: 159-163.

21. Zhang SS. Subarachnoid hemorrhage and epileptic seizures. Chung Hua Shen China Ching Shen ko Tsa Chih 1982; 15: 213-215.

22. Drake CG. Cerebral arteriovenous malformations: considerations for and experience with surgical treatment in 166 cases. Clin Neurosurg 1979: 26: 145-208.

23. Grab CJ, Perret GE, Torner JC. Bleeding from cerebral arteriovenous malformations as part of their natural history. J Neurosurg 1983: 58: 331-337.

24. Tay $\mathrm{CH}$, Oon $\mathrm{Cl}$ et al. Intracranial arteriovenous malformations in Asians. Brain 1971; 94: 61-68.

25. Perret $G$, Nishioka $H$. Report on the cooperative study of intracranial aneurysms and subarachnoid hemorrhage: Section VI - arteriovenous malformations. J Neurosurg 1966: 25: 467: 490.

26. Parkinson D, Bachers G. Arteriovenous malformations: Summary of 100 consecutive supratentorial cases. J Neurosurg 1980;53: 285-299.

27. Feffer SE, Parray HR, Wastring DW. Seizure after infusion of aminocaproic acid. JAMA 1978; 240: 2468.

28. Yamaura A. Nakamura $T$ et al. Cerebral complication of antifibrinolytic therapy in the treatment of intracranial aneurysm. Eur Neurol 1980: 19: 77-84. 